\title{
Caminhos e descaminhos do retorno à escola: o Programa Ação Integrada Adultos
}

Márcia Regina da Silva Isabel Bilhão

\section{Resumo}

O artigo se insere no campo temático da Educação de Jovens e Adultos, seus objetivos são: apresentar as peculiaridades de um programa municipal desenvolvido na cidade de Esteio/RS, o Programa Ação Integrada Adultos; identificar as características da escola e da turma que embasaram a investigação e refletir sobre as histórias de vida e perspectivas dos sujeitos de pesquisa. A metodologia constituiu-se da análise dos documentos referentes ao Programa, observações das práticas pedagógicas e atividades escolares e realização de entrevistas semi-estruturadas. Pretende-se contribuir para o aprofundamento das discussões sobre diferentes modalidades de EJA refletindo, a partir desse estudo de caso, sobre suas possibilidades, limites e contradições.

Palavras-chave: Educação de Jovens e Adultos. Histórias de vida. Programa Ação Integrada Adultos. 


\title{
Ways and waywardness of the return to school: Integrated Action Adults Program
}

\begin{abstract}
The article is included in the field of Youth and Adult Education. The objectives of the analysis are: to present the peculiarities of the of a municipal program developed in the city of Esteio/RS, the Integrated Adults Action Program; identify the characteristics of the school and the class that underpin the research and reflect about the stories of life and future prospects of research subjects. The methodological approach is from the analysis of the documents relating to the Program, observations of teaching practices and school activities and carrying out semi-structured interviews. We intend to contribute to the deepening of discussions about different types of Youth and Adult Education reflecting, from this case study, on its possibilities, limits and contradictions.
\end{abstract}

Keywords: Youth and Adult Education. Life stories. Adults Integrated Action Program.

\section{Caminos y descaminos del retorno a la escuela: el Programa Acción Integrada Adultos}

\section{Resumen}

El artículo se inscribe en el campo temático de la Educación de Jóvenes y Adultos, sus objetivos son: presentar las peculiaridades de uno programa desarrollado en la ciudad de Estaio/RS, el Programa Acción Integrada Adultos; identificar las características de la escuela y de la clase que basaran la investigación y reflejar sobre las historias de vida y perspectivas de los sujetos de investigación. La metodología consiste del análisis de los documentos referentes al Programa, observaciones de las prácticas pedagógicas y actividades escolares y realización de entrevistas semiestructuradas. Se pretende contribuir a la profundización de las discusiones sobre diferentes modalidades de EJA reflejando, a partir de ese estudio de caso, sobre sus posibilidades, límites y contradicciones.

Palabras-clave: Educación de Jóvenes y Adultos. Historias de vida. Programa Acción Integrada Adultos. 


\section{Chemins et détours de retour à l'école: le Programme Action Intégré Adultes}

\section{Résumè}

L'article est compris dans le domaine de l'éducation pour jeunes et adultes, les objectifs sont: présenter les particularités d'un programme municipal développés dans la ville de Esteio/RS, le Programme Action Intégrée Adultes; identifier les caractéristiques de l'école et la classe qui a soutenu la recherche et réfléchir sur les histoires de vie et les perspectives des sujets de recherche. La méthodologie est à l'analyse des documents liés au Programme, observations des pratiques d'enseignement et des activités scolaires et réalisation d'entretiens semi-structurés. Il est destiné à contribuer à l'approfondissement des discussions sur les différents modalités de l'éducation pour jeunes et adultes reflétant, à partir de cette étude de cas, sur ses possibilités, limites et contradictions.

Mots-clés : Éducation pour jeunes et adultes. Histoires de vie. Programme Action Intégrée Adultes.

\section{Introdução}

A presente reflexão se insere em um campo de estudos bastante vasto. Em uma pesquisa realizada na Biblioteca Digital Brasileira de Teses e Dissertações, utilizando-se o descritor Educação de Jovens e Adultos/EJA, foram encontradas 227 dissertações e 842 teses, perfazendo o total de 1.069 títulos $^{1}$. Na impossibilidade de mapear tamanha discussão, pretende-se apenas indicar duas das tendências analíticas observadas em estudos realizados na última década ${ }^{2}$. A primeira se refere aos motivos de frequência à EJA, apontando que, entre os adultos, essa decisão ainda está muito ligada ao trabalho - seja para ingressar ou permanecer no emprego, deixar a informalidade, ou na expectativa de melhoria salarial - e que, para um crescente número de jovens, a EJA se tornou a forma de abreviar o

1 Disponível em: <http://bdtd.ibict.br/>. Acessado no período de maio a julho de 2015.

2 Por exemplo: Caldeira (2011), Vale (2012) e Ferrari (2014). 
tempo de permanência na escola ou a possibilidade de conclusão dos estudos após repetidas reprovações. A segunda tendência relaciona-se ao reconhecimento da necessidade de se aprofundar a reflexão sobre as especificidades dessa modalidade de ensino. Nesse sentido, muitas investigações tratam da legislação e das diretrizes curriculares específicas, da formação continuada de professores e profissionais atuantes na área, da produção de materiais didáticos ou da observação dos distintos contextos de vida dos estudantes.

Neste artigo pretende-se participar desse amplo diálogo a partir da abordagem de um programa específico de EJA, o Programa Ação Integrada Adultos/PAIA, que tem como característica o fato de ser ofertado a estudantes com 23 anos ou mais e que tenham concluído a 5a série ou o 6ㅇ ano do Ensino Fundamental. A análise aqui apresentada é parte de uma Dissertação de Mestrado $^{3}$ realizada a partir do acompanhamento de uma turma desse Programa. Os objetivos são: apresentar o Programa, com base em sua trajetória e características de funcionamento; identificar as peculiaridades da turma estudada e analisar as histórias de vida e os projetos de futuro relatados pelos sujeitos de pesquisa a partir de seu retorno à escolarização ${ }^{4}$.

Optou-se por uma abordagem qualitativa com base nos seguintes procedimentos metodológicos: análise dos documentos referentes ao Programa e à organização da Escola, coleta de dados objetivos referentes à turma, relato das observações do cotidiano das aulas e atividades realizadas ao longo do ano de 2014 , e análise das entrevistas com a supervisora escolar, com a professora titular, com a coordenadora Municipal do Programa e com uma amostra dos estudantes sujeitos da pesquisa.

O artigo está assim organizado: na primeira seção, contextualiza-se brevemente o campo empírico e apresentam-se as características do PAIA. Na segunda, analisamse as trajetórias e perspectivas observadas nas narrativas dos alunos entrevistados e, na terceira, reflete-se sobre os impasses, contradições e alcances do Programa com base na comparação entre as concepções apresentadas na documentação e as observações realizadas ao longo da investigação.

3 Intitulada XXXXX, defendida junto ao Programa de Pós-Graduação XXXXX. Agradecemos aos professores XXXX e XXXX pelas preciosas colaborações ao longo do processo.

4 A pesquisa foi aprovada pelo Comitê de Ética em Pesquisa da XXXX, conforme a Resolução 466/12 do Conselho Nacional de Saúde. 


\section{Aproximação ao campo empírico}

As formulações apresentadas embasam-se no estudo de uma turma do Programa Ação Integrada Adultos/PAIA, sediado em um Centro Municipal de Educação Básica/ CMEB, situado no Município de Esteio, na Região Metropolitana de Porto Alegre, RS. Essa escola atualmente conta com 1.150 alunos, atendidos desde a Educação Infantil até a EJA, nos turnos manhã, tarde e noite.

A instituição, fundada no final dos anos 1970, está situada em um bairro considerado de grande vulnerabilidade social. O aumento significativo da população vem alterando tanto a organização escolar quanto o perfil do público frequentador. Segundo dados fornecidos pela equipe diretiva da escola, grande parte dos alunos da EJA trabalham na informalidade, principalmente na construção civil, na reciclagem de resíduos e no comércio local. No bairro existem poucos espaços destinados ao lazer. As praças, a quadra de esportes e o comércio estão concentrados na avenida central, na qual a escola também está localizada.

De acordo com o Projeto Político Pedagógico/PPP da escola, a metodologia da EJA deve pautar-se por um currículo interdisciplinar baseado em projetos de trabalho. As estratégias para a efetivação de tal proposta são discutidas nas reuniões pedagógicas que ocorrem semanalmente com a participação de todos os professores. Os projetos interdisciplinares devem se basear nas falas significativas e nas necessidades dos alunos. A avaliação é semestral, apresentada por meio de pareceres descritivos.

A partir de 2010 a escola, que já ofertava EJA há uma década, passou a trabalhar também com o PAIA. No Regimento Padrão do Programa (Esteio, Smee, 2009-2012) consta que este tem por finalidade oportunizar a adultos trabalhadores, a partir dos 23 anos, a conclusão do Ensino Fundamental baseando-se em "uma proposta pedagógica diferenciada e interdisciplinar que articule os saberes construídos em suas trajetórias pessoais e profissionais com o conhecimento cientificamente construído pela humanidade", visando à formação de "sujeitos conscientes de seu papel na sociedade, considerando as necessidades dos educandos". (Esteio, Smee, 2009-2012, p. 4).

A Coordenadora Municipal do Programa explicou que inicialmente houve um convênio, de 2010 a 2012, entre a Prefeitura Municipal de Esteio e o Instituto Integrar ${ }^{5}$, vinculado ao Sindicato dos Metalúrgicos de São Paulo, que deu início ao Projeto Integrar. A partir de 2013 a Secretaria Municipal de Educação e Esporte Smee passou a coordenar o Programa, que então foi denominado Ação Integrada,

5 O Instituto Integrar foi fundado pela Confederação Nacional dos Metalúrgicos da Central Única dos Trabalhadores - CNM/CUT, em 1996 e desenvolve projetos de formação e qualificação profissional. No Rio Grande do Sul atua desde 1997. Disponível em: <http://www.integrar.org.br/>. 
dividido em Adolescentes (entre 15 e 18 anos) e Adultos (23 anos em diante). Ao longo do período de convênio, o Município de Esteio chegou a adotar os livros didáticos elaborados pelo Instituto Integrar.

Decorridos dois anos, a Smee criou seu próprio Regimento de trabalho, pois algumas dificuldades geradas pelo convênio precisavam ser superadas, entre elas, o fato de que quem certificava os alunos não era a escola onde eles estudavam, e sim o Instituto Federal de Educação, Ciência e Tecnologia Sul-Rio-Grandense - IFSUL, de Pelotas. Com o apoio dos professores ligados à EJA e da assessoria pedagógica da Smee foi construído o Programa Ação Integrada, aprovado pelo CME - Conselho Municipal de Educação, no final do ano de 2010, para que em 2011 os alunos pudessem ser matriculados e certificados diretamente nas escolas da Rede Municipal. Ou seja, a Prefeitura de Esteio, com base no estabelecido nas Diretrizes Curriculares Nacionais para a $E \mathrm{~A}^{6}$, transformou o antigo convênio em uma política municipal diferenciada e específica para a conclusão do Ensino Fundamental, ofertada ao público com idade superior aos 23 anos. O Programa não se estende para o Ensino Médio e não possui correspondente nos âmbitos estadual e federal de ensino.

Ainda segundo a Coordenadora, o principal objetivo do Programa é reconciliar o aluno com a educação escolar, motivando-o a retornar e concluir os estudos. A escolha dos professores baseia-se na indicação da direção da escola, em concordância com a Smee, sendo requisito que estes possuam formação compatível e experiência na EJA. A Coordenadora observou também que, a cada ano letivo as escolas optam pelo funcionamento ou não do Programa, que pode ocorrer nos turnos diurno e noturno, destinando-se a adolescentes e/ou adultos.

Entre os objetivos do PAIA estão o desenvolvimento de metodologias interdisciplinares e interativas, a valorização dos saberes prévios dos educandos, a promoção de sua realização no mundo do trabalho, a construção de conceitos necessários ao pleno exercício da cidadania por meio das diferentes leituras do mundo, o desenvolvimento da autonomia e da criticidade, a qualificação das diversas formas de expressão, aprimoramento da leitura e interpretação a partir de diversas situações do cotidiano, o trabalho a partir das dificuldades e das necessidades específicas de cada turma e o estimulo à criatividade e à curiosidade (Esteio, Smee, 2009-2012, p. 7).

A inserção no campo empírico iniciou-se no mês de abril de 2014. A turma, que havia recebido 37 matrículas, era então composta por 19 alunos, 11 mulheres e 8 homens, cuja faixa etária variava de 24 a 61 anos. Deste grupo, apenas um indivíduo não possuía escolaridade prévia na EJA e 16 já haviam estudado naquela escola em distintos períodos, entre 1978 e 2013. Em relação ao trabalho, 17 alunos exerciam

6 Conforme o Art. $6^{\circ}$ da Resolução CNE/CEB N 1, de 5 de Julho de 2000, "Cabe a cada sistema de ensino definir a estrutura e a duração dos cursos da Educação de Jovens e Adultos, respeitadas as diretrizes curriculares nacionais, a identidade desta modalidade de educação e o regime de colaboração entre os entes federativos". (BRASIL, 2000a). 
atividade remunerada (a maioria na informalidade), e 2 encontravam-se sem ocupação remunerada. A professora titular cursou Magistério, no ensino secundário, e duas Licenciaturas, Estudos Sociais e Geografia. Além disso, tem ampla experiência docente: trabalhou 25 anos nas séries iniciais do Ensino Fundamental da Rede Municipal e atua na EJA desde 2005, participando de três edições do PAIA. Além da professora titular, a turma também tinha aulas com os professores de Educação Física e Língua Inglesa.

A escola é responsável pela divulgação local do Programa. Uma estratégia tem sido o anúncio da oferta nos estabelecimentos comerciais da comunidade e também por meio dos alunos que já o conhecem. A direção realiza as entrevistas iniciais com os interessados. Geralmente o número de ingressantes é maior do que o de concluintes. No caso da turma pesquisada, dos 19 alunos frequentes quando do início da observação, 14 permaneceram até o final.

Ao longo das entrevistas iniciais, a professora também salientou sua preocupação em incentivar os alunos a continuarem estudando e informou que alguns dos concluintes de edições anteriores do Programa encontravam-se em escolas da Rede Estadual cursando o Ensino Médio. No entanto, como não há um acompanhamento mais sistemático do percurso dos egressos, não foi possível apurar números precisos sobre essa continuidade.

Outra questão relevante, apontada pela professora, foi a de que ao longo do ano de permanência no Programa os estudantes realizam saídas culturais. A turma observada já havia inclusive visitado a Usina do Gasômetro e a Fundação Iberê Camargo ${ }^{7}$, em Porto Alegre. Como se verá adiante, a questão das saídas foi retomada por alguns dos alunos entrevistados que mencionaram o fato de que, se não fosse pela escola, provavelmente nunca teriam acesso a esses espaços. No tópico a seguir, apresentamse as entrevistas dos sujeitos de pesquisa e retoma-se esta questão.

\section{Relatos de vida e reflexões sobre a experiência escolar}

Como mencionado, nesse tópico analisam-se alguns aspectos apresentados nas entrevistas realizadas com cinco integrantes da turma pesquisada. O principal critério dessa seleção foi a intenção de obter uma amostra que refletisse minimamente a diversidade do grupo. Durante a realização das observações, consolidou-se a opção de escolher entrevistados de diferentes faixas etárias, dos gêneros masculino e feminino. Também foram levadas em consideração algumas indicações feitas pela

7 A Usina do Gasômetro forneceu energia elétrica à base de carvão de 1928 a 1974. Em 1991 tornou-se um centro cultural do trabalho. A Fundação Iberê Camargo preserva e divulga a obra do artista e incentiva e expõe produções de arte contemporânea. 
professora titular. As entrevistas foram realizadas ao longo dos meses de outubro e novembro de 2014 , portanto, em um momento em que os participantes estavam próximos à conclusão do Programa ${ }^{8}$.

No primeiro contato estabeleceu-se que as identidades dos participantes seriam mantidas em sigilo e que estes seriam apresentados com nomes fictícios, escolhidos por eles. Essa medida reflete um duplo cuidado: não expô-los a situações constrangedoras em função de suas falas e opiniões e procurar, com base no anonimato, garantir relatos mais fluídos e espontâneos. Além disso, a aproximação ao grupo de entrevistados levou em consideração a advertência, feita pelo sociólogo Michael Pollak, de que

[...] contar a própria vida nada tem de natural. Uma pessoa a quem nunca ninguém perguntou quem ela é, de repente ser solicitada a relatar como foi a sua vida, tem muita dificuldade para entender este súbito interesse. Já é difícil fazê-la falar, quanto mais falar de si (Pollak, 1992, p. 13).

Portanto, os primeiros contatos com o grupo de entrevistados visaram esclarecer dúvidas e construir laços de confiança e empatia, sem os quais não ocorreria a adesão ao projeto. Uma vez engajado, o grupo foi composto da seguinte forma: dois homens, um com 49 e outro com 61 anos e três mulheres, com idades que variavam dos 32 aos 55 anos. Os homens escolheram identificar-se como JC e Adriano, e as mulheres como Flor do Campo, Betão, e Pink.

As entrevistas foram do tipo semiestruturadas, baseadas em um roteiro com as seguintes perguntas:

- Como foi tua vida escolar antes de ingressares no Programa Ação Integrada Adultos?

- Conta sobre essa volta aos estudos. O que te motivou?

- Como foi tua experiência no Programa Ação Integrada Adultos?

- Pretendes continuar estudando?

Tais questões tinham a pretensão de estimular relatos sobre as histórias de vida, especialmente em relação às trajetórias escolares, bem como sobre as vivências atuais e expectativas de futuro, constituídas a partir das novas experiências e conhecimentos adquiridos no Programa. Essa proposta foi construída com base em algumas reflexões de Marie-Christine Josso, para quem,

8 O Programa tem duração de um ano letivo e a turma em questão concluiu as atividades no mês de dezembro de 2014. 
Os relatos de histórias de vida permitem confirmar uma constatação importante para legitimar a importância das práticas de explicitação e de desenvolvimento de projetos de formação: o caráter extremamente heterogêneo das motivações, necessidades e desejos que dinamizam o investimento de estudantes adultos (Josso, 2006, p.27).

A seguir apresenta-se a síntese das respostas e reflexões realizadas 9 . Em relação à primeira questão - Como foi tua vida escolar antes de ingressares no programa Ação Integrada Adultos? - predominaram narrativas marcadas pela noção de "infância sofrida", através da qual foram apontadas dificuldades ligadas à pobreza, precariedade da organização familiar, doença e ingresso prematuro ao mundo do trabalho. Destacam-se a seguir alguns exemplos.

O entrevistado JC salientou que na localidade onde vivia, no interior do Rio Grande do Sul, não havia prédio escolar ${ }^{10}$ : "No começo, de menino ainda, a gente era muito difícil de estudar, não existia colégio, então eu ia numa igreja, Igreja São Pedro, e nessa igreja eu me batizei, fiz a primeira comunhão e fui aluno também dentro dessa igreja"(JC, 06/10/2014).

O entrevistado Adriano mencionou outra situação extrema:

Na época, a situação dos meus pais não era boa, então eu lembro que quando eu cheguei a estudar, sinceramente, tinha dias e não foi poucos, não tinha nem o que comer em casa [...] um dia eu cheguei na escola tão encarangado que a professora me levou lá para a sala da diretora e me deram, não lembro o que, um chá, um café. E me deram uma blusinha de presente, que eu não conseguia pegar nem o lápis para escrever de tanto frio (Adriano, 15/10/2014).

A entrevistada Betão ao ser perguntada a respeito da sua vida escolar, respondeu: "Foi horrível! Perdi minha mãe com cinco anos, aí fiquei morando com a minha vó e ela tinha um filho adotivo. Que a gente não podia passar de ano dele na escola, se a gente avançasse ela tirava nós do colégio" (Betão, 05/11/2014).

Para Flor do Campo a frequência à escola foi acompanhada de grande sofrimento físico, causado pela doença que a acomete ao longo da vida e que a tornou cadeirante aos quatro anos de idade. Segundo ela: "Comecei a estudar com 12 anos, né? Primeira, segunda e terceira. Aí parei com 15. Eu, sempre muito doente. Aí eu parei de estudar. Aí comecei com 22 de novo. Aí fiz a terceira, a quarta e a quinta. Vivia doente, vivia no hospital, né?" (Flor do Campo, 28/10/2014).

Esses excertos foram escolhidos porque apontam para situações de extrema dificuldade, exemplificando alguns dos muitos casos de superação e resiliência que

9 Na transcrição das respostas foi mantido o tom coloquial, próprio da narrativa oral.

10 Tal situação remete à falta de prédios escolares em várias regiões do Brasil, pelo menos até o início dos anos 1960. Para o caso do RS a expansão do ensino elementar deu-se no governo Leonel Brizola (1959 a 1963). Sobre o assunto ver: Quadros (2005). 
marcam a vida de adultos que retornam à escola. Cada um dos entrevistados salientou diferentes obstáculos: miséria, doença, inexistência de escola, desestruturação familiar. O ponto em comum é o fato de terem interrompido antes de completarem o Ensino Fundamental. Não se aprofundará a análise da evasão escolar no âmbito deste artigo. Mas é interessante notar que duas de suas causas mais comuns também aparecem nos relatos desse grupo. A primeira, o ingresso precoce no mercado de trabalho, mencionada da seguinte forma por Adriano: "Já com uns oito, dez anos eu comecei a trabalhar. Eu trabalhava numa olaria com meu avô. Ele era daquele tipo antigo sabe? Era analfabeto também, não sabia nem assinar o nome dele" (Adriano, 15/10/2014). E, a segunda, a gravidez na adolescência. Assim relatada por Pink: "Bom, eu estudei até a oitava. Na verdade, tinha tipo 16, estudei, não parei de estudar, reprovei uns ano, mas continuei. [...] Aí, desisti porque engravidei, então parei de estudar" (Pink, 20/11/2014).

No primeiro caso pode-se constatar que a noção de infância, como construção histórica ${ }^{11}$, está diretamente ligada ao contexto de vida dos sujeitos. Nesse sentido, note-se que geralmente a abreviatura da infância relaciona-se à supressão da vida escolar. Muitos adultos, ao retornarem à escola buscam um direito de cidadania que Ihes foi negado na infância. No segundo caso, presente no relato de Pink, observa-se a precipitada transição para a vida adulta e suas responsabilidades. Neste sentido, a gestação na adolescência é, de modo geral, enfrentada com dificuldade porque:

Nessa transição abrupta do seu papel de mulher, ainda em formação, para o de mulhermãe, a adolescente vive uma situação conflituosa e, em muitos casos, penosa. A grande maioria é despreparada física, psicológica, social e economicamente para exercer o novo papel materno, o que [...] associado à repressão familiar, contribui para que muitas fujam de casa e abandonem os estudos. (Moreira, Viana, Queiroz e Jorge, 2008, p. 315-316).

Pink reforçou que quando seu filho tinha dois anos, retornou à escola, frequentou-a por um período de três meses e desistiu novamente devido às dificuldades de conciliar a vida escolar e os encargos da maternidade. Seu relato exemplifica muito do que foi apontado pelos autores acima. Ela não mencionou conflitos com os familiares, nem mesmo com o pai do seu filho, porém deixou clara a preocupação com o olhar da sociedade diante de sua situação, que foi decisiva para que abandonasse os estudos no último ano do Ensino Fundamental. Em uma frase inconclusa refletiu: "Só desisti porque adolescente, barriguda..." (Pink, 20/11/2014).

A segunda questão - Conta sobre essa volta aos estudos. O que te motivou? provocou relatos acerca dos diferentes caminhos percorridos pelos entrevistados, desde a intenção até a decisão de retomar os estudos. Cada um deles rememorou uma trajetória marcada por rupturas, dificuldades, mudanças de rumo que interferiram

11 Para uma leitura mais aprofundada sobre a noção de infância como construção histórica, ver: Kuhlmann (2000) e Ariès (1981). 
diretamente em suas escolhas. Entretanto, mesmo com todas as suas peculiaridades, ao se matricularem no Programa, todos foram classificados como "adultos", pois esta definição baseou-se no fator etário, estabelecido com a idade mínima de ingresso, aos 23 anos. Todavia, deve-se observar que o fator maioridade, não é o único e talvez não seja nem mesmo o mais esclarecedor na definição do "ser adulto".

Em uma leitura sociológica dessa noção, Oliveira, Rios-Neto e Oliveira, apontam para a expectativa social da efetivação de quatro eventos, não necessariamente simultâneos. São eles:

[...] sair de forma definitiva da escola; encontrar um trabalho temporário ou permanente por meio do qual o indivíduo possa suprir a si ou a uma possível família dos recursos materiais necessários à sobrevivência; formar a primeira união relativamente estável, ou seja, viver com o companheiro em uma mesma residência; e, por fim, ter o primeiro filho (Oliveira, Rios-Neto e Oliveira, 2006, p. 1).

Ao longo de suas narrativas, alguns dos entrevistados apontaram para aspectos que marcaram a passagem da adolescência para a vida adulta que se encontram em consonância com os fatores acima. Para JC, Adriano e Betão, o "ser adulto" ocorreu pela via do ingresso precoce no mercado de trabalho. Para Pink, a maternidade exigiu responsabilidades de pessoa adulta, afastando-a dos estudos. Todavia, esses eventos não abarcam a totalidade do complexo processo de tornar-se adulto. Flor do Campo, por exemplo, devido a suas condições de saúde, transitou para a maioridade em um contexto no qual não estão presentes o trabalho remunerado, a maternidade ou a independência domiciliar.

Essas diferenças apontam para outra constatação, observada pelos mesmos autores, a de que "[...] nas diversas sociedades, há pessoas que jamais completarão todo o processo" (Oliveira, Rios-Neto e Oliveira, 2006, p. 1). Entretanto, independente de suas peculiares, os estudantes observados foram considerados aptos a ingressarem em uma turma de adultos. Nas narrativas a seguir podem-se perceber algumas das variáveis apresentadas pelos entrevistados para justificar seu retorno à vida escolar.

JC havia frequentado até a quinta série do ensino fundamental e estava há mais de quarenta anos afastado da escola. Contou que, depois de ingressar no mercado de trabalho, havia realizado diversos cursos técnicos pelo Serviço Nacional de Aprendizagem Industrial/Senai e que essa formação lhe garantiu um bom emprego. Essa situação mudou quando, em 1993, "a empresa entrou em crise e como eu tinha um salário muito alto, fui o primeiro a ser demitido" (JC, 06/10/2014). A partir desta nova realidade, JC tornou-se autônomo, trabalhando em sociedade com um amigo: "Compramo um caminhão pequeno, é semi-novo, prá transportá GLP [gás de cozinha]" (JC, 06/10/2014). Essa situação de vida individual remete a um contexto mais amplo, de reestruturação produtiva ocorrida no país ao longo dos anos 1990, que acarretou "a diminuição crescente do emprego industrial e a expansão do setor 
de serviços" (Druck, 1999, p. 43).

No relato de JC, o fator trabalho não é mencionado como algo preponderante em seu retorno à escola, para ele a ampliação da escolarização não representaria nenhum benefício imediato nesse aspecto. Mais importante em sua decisão foi a percepção da desorganização de seu tempo, primeiro como desempregado e depois como autônomo. O excesso de tempo livre, de não trabalho, tornou-se um pesado fardo e passou a afetar sua estabilidade emocional. Em suas palavras: "E como antes eu tinha um horário muito puxado, e depois eu fiquei em casa eu me senti muito mal. E aí eu fiquei assim até meio fora da casinha. Até que eu cheguei aqui, bem complicado" (JC, 06/10/2014).

A essa percepção da necessidade de ocupar seu tempo "com algo produtivo", JC acrescentou a pretensão de "buscar o que perdi e me atualizar no ensino". Entretanto, a questão decisiva parece ter sido a iniciativa de sua esposa - estudante do Curso de Pedagogia - que realizou sua matrícula e incentivou-o a frequentar as aulas.

Para Flor do Campo, o fator trabalho também não pesou no retorno à escola. Em sua narrativa a questão mais difícil a ser vencida, ao contrário do que ocorreu com JC, foi justamente a oposição familiar. Sua mãe, temerosa por sua saúde e pelos perigos de sair à noite, preferia que ela não voltasse a estudar. Sua estratégia foi narrada da seguinte maneira: "Esse ano peguei e vim sozinha, me matriculei e depois cheguei em casa, contei pra ela, comprei material também já, né?" (Flor do Campo, 28/10/2014). A estratégia parece ter obtido sucesso uma vez que, a despeito de suas dificuldades, ela conseguiu permanecer no Programa e concluir o Ensino Fundamental.

Já para Adriano, Pink e Betão a decisão de matricular-se no Programa justificou-se pelas demandas do mercado de trabalho. No caso de Adriano e de Pink, a expectativa era de ampliarem suas chances de conseguir melhores colocações. Nas palavras dele: "Na prática eu sei tudo, faço tudo. Só que eu já perdi muita oportunidade em empresa grande por não ter estudo. A gente chega lá com a prática, e pra eles não interessa. Não tenho o canudo" (Adriano, 15/10/2014). E, nas palavras dela:

Até pra servente de limpeza precisa ter e eu não tinha [Ensino Fundamental completo]. Ai eu não conseguia nada, eu fiquei uns quatro meses desempregada, não conseguia porque não tinha estudo. Agora tenho certeza que final do ano eu pego ali o diploma, daí já consigo outra coisa melhor (Pink, 20/11/2014).

Para Betão, o fator preponderante de ingresso no Programa foi a pressão da empresa em que trabalha para que ela conclua o Ensino Fundamental: "Eu voltei, mas agora porque a firma tá exigindo, senão, não taria aí" (Betão, 05/11/2014). Ressalte-se que mais ou menos três anos antes ela tentou concluir o Ensino Fundamental e novamente se frustrou. Portanto, não chega a ser estranho que sua fala demonstre uma atitude bastante defensiva. Todavia, deve-se levar em consideração o fato de que, mesmo tendo participado do Programa e estando prestes a concluir o Ensino 
Fundamental, sua confiança em relação à capacidade de aprender ainda continuava bastante abalada. Essa é uma interpretação possível para a seguinte frase: "Vou ser bem sincera, não tenho cabeça pra tá dentro de uma sala de aula, não gosto!" (Betão, 05/11/2014).

Estes fragmentos dos relatos foram selecionados porque permitem pensar a respeito das singularidades das histórias de vida, os diversos caminhos, pessoas, situações que levaram os entrevistados a retornarem ao ambiente escolar, conciliando-o com os mais variados aspectos e demandas de suas vidas. Com base nas reflexões propostas por Gilberto Velho, pode-se, por um lado, refletir sobre os fatores implicados na construção de seus "campos de possibilidades":

[...] Família, trabalho, religião, lazer, opções políticas, entre outros, configuram um campo de possibilidades em que os atores individuais se movem, mais ou menos impelidos e pressionados, mas com uma gama básica de alternativas e opções (Velho, 1994, p. 79).

Por outro lado, deve-se observar, em concordância com as ponderações de Miguel Arroyo, que uma expectativa ingênua, por parte de instituições e de educadores, de vincular o retorno à escola ao mercado formal de trabalho - num contexto de grande instabilidade econômica e de crise de empregos - pode levar tanto a frustrações dos indivíduos quanto à restrição do papel desempenhado pela escola. Nas palavras do autor: "Qualquer tentativa de fazer da EJA um centro de formação de competências para um trabalho que não existe já é um fracasso". Para ele, não deveria se tratar "de um currículo para mantê-los na sobrevivência, mas para serem mais livres no presente, terem mais opções de superá-la, sem promessas ingênuas de futuro" (Arroyo, 2007, p. 11-12).

As duas últimas questões - Como foi tua experiência no Programa Ação Integrada Adultos? Pretendes continuar estudando? - foram realizadas de forma complementar e procuraram refletir sobre como eram percebidos os saberes e aprendizagens construídos pelos entrevistados, no âmbito escolar ou fora dele, como estes dialogavam com a experiência de ser estudante do Programa, e em que medida podiam relacionar-se com a intenção ou não de continuarem os estudos.

As respostas, bastante variadas, oscilaram da total falta de reconhecimento aos saberes construídos fora do âmbito escolar ao elogio do conhecimento constituído no contexto profissional. Exemplificando o primeiro caso, Adriano ponderou: "Quando eu comecei aqui não sabia praticamente nada. Esse ano aprendi muita coisa" (Adriano, 15/10/2014). E, no segundo caso, Betão respondeu:

Eu prefiro tá trabalhando do que tá na escola. A máquina que eu opero, chegou nova, como ninguém sabia como usar. Daí foi eu, o encarregado e mais um colega meu pra fazê o curso em Caxias12. Eu trabalhei em várias firma, e essa é a única que gostei de trabalhar (Betão, 05/11/2014).

12 Caxias do Sul, cidade da Serra Gaúcha, é o mais importante pólo metal-mecânico do RS. Betão se refere ao fato de ter recebido treinamento na indústria que forneceu a nova máquina a sua empresa. 
Para outros o fator preponderante da experiência no Programa não passou especificamente pela constituição ou relação entre saberes formais, mas sim pela constituição de sociabilidades e por relações de afeto. Pink, por exemplo, destacou a convivência e as amizades. Segundo ela, lembrará sempre

Das professoras e dos colegas [...] que são muito queridos, principalmente a professora que, nossa, ela tá sempre assim, a gente falta dois dias e ela tá mandando mensagem. Ela se preocupa, então não é aquela coisa aluno aqui só no colégio, não. Fora do colégio também ela se preocupa (Pink, 20/11/2014).

A narrativa de Flor do Campo, por seu turno, enfatizou dificuldades e temores superados ao longo do Programa: "Eu tava com medo de chegar, de dar empecilho, fiquei com medo de conhecer os professores e tudo, né? A turma ficou amiga. Aí me senti bem, tô em casa" (Flor do Campo, 28/10/2014). A entrevistada manifestou o receio "de dar empecilho", significando dar trabalho aos outros, devido à sua condição física, situação que precisou ser superada tanto em seu imaginário quanto na prática da organização escolar, visto que a escola, de fato, não contava com uma rampa de acesso à sala de aula. Flor do Campo precisou solicitar à direção da escola que a rampa fosse construída. Em suas palavras: "A professora me ajudava, os outros colegas me ajudavam a entrar e sair, né? Eles fizeram na mesma semana, não levou 15 dias, fizeram a rampa pra mim já [...] eu pedi, fui atrás" (Flor do Campo, 28/10/2014).

Além da conquista da rampa, Flor do Campo salientou as situações vivenciadas em ambientes externos à escola, especialmente relacionadas às atividades culturais: "[...] Me ajudam também no ônibus. Até fomos no cinema em Porto Alegre e São Leopoldo. JC me ajudou o tempo todo lá, me levou na cadeira empurrando" (Flor do Campo, 28/10/2014).

A partir de outro aspecto, as atividades culturais também marcaram a narrativa de Pink. Ela destacou o fato de terem assistido a apresentação de um coral no centro da cidade e a ida ao cinema, enfatizando a medição da escola: "Só com o colégio, quando o colégio vai" (Pink, 20/11/2014).

A análise desses fragmentos permite apontar para alguns aspectos relevantes. Entre eles, o fato de que, ao concluir o Ensino Fundamental, persiste nas narrativas de Adriano e Betão a dissociação entre os conhecimentos práticos, ligados à profissão, e os conhecimentos escolares. Assim, observa-se que pelo menos nesses exemplos o objetivo regimental do Programa de constituir-se em "uma proposta pedagógica diferenciada e interdisciplinar que articula os saberes construídos em suas trajetórias pessoais e profissionais com o conhecimento cientificamente construído pela humanidade" (Esteio, Smee, 2009-2012, p. 4), ainda não se efetivou.

Na narrativa de Flor do Campo percebe-se uma situação ainda muito presente na vida de pessoas com deficiência, o fato de desconhecerem o direito de acessibilidade, 
estabelecido em lei ${ }^{13}$. Ela referiu-se à construção da rampa como um favor por parte da equipe diretiva. Entretanto, sua mobilização pessoal e o fato de ter sido rapidamente atendida, indicam um aprendizado tanto para ela quanto para a escola - que também Ihe providenciou uma mesa adaptada, a fim de facilitar o manuseio do material escolar. Tais medidas, provavelmente, contribuirão para que esse ambiente escolar se adéque melhor às necessidades dos próximos alunos.

A ênfase nas saídas para atividades culturais, observadas nas falas de Flor do Campo e Pink, podem indicar não apenas a superação das barreiras físicas, muito presentes no caso da primeira, mas especialmente das barreiras sócio-culturais, presentes na vida de todo o grupo. Não se pretende aprofundar a análise das inúmeras interdições tácitas ou explícitas que impedem o acesso a bens culturais à grande parte da população. Entretanto, é importante salientar que essas experiências mediadas pela escola podem representar uma oportunidade de acesso ao "capital simbólico" - na acepção de Pierre Bourdieu (2005, p. 57) - que até então havia sido negado à maioria deles. O quanto dessa vivência será incorporada às práticas futuras é impossível dizer. Mas, a julgar pela ênfase das afirmativas, parece ter se constituído em algo de fato marcante no presente.

Em relação à continuidade nos estudos, as respostas variaram da certeza absoluta em não continuar, expressa na seguinte fala de Betão: "Ah não, na escola não!", que afirmou em seguida a intenção de realizar cursos técnicos, voltados ao aperfeiçoamento no trabalho: "Eles dão né? Eu já fiz alguns lá, e agora ele [empregador] tá pra me dar um de solda, que eu andei conversando com ele" (Betão, 05/11/2014).

Até narrativas que permitem perceber uma grande tensão entre a vontade e as dificuldades. JC e Adriano apontaram especialmente para os problemas em conciliar horários de trabalho, demandas familiares e a manutenção da rotina escolar. Para Flor do Campo os problemas de deslocamento, acesso e segurança tornam-se ainda mais evidentes: "Não pretendo, não dá, é muito frio, muito longe os colégios. Não tem uma condução própria para cadeirantes". E acrescenta, "Se puder fazer uns cursos de computação pra aprender a mexer no computador, fazer pesquisas, abrir pastas. Quanto mais aprender melhor" (Flor do Campo, 28/10/2014).

Esse aspecto da resposta de Flor do Campo faz pensar que o acesso às tecnologias digitais permitiria a eliminação das barreiras físicas entre ela e o conhecimento, possibilitando-Ihe inclusive a realização do Ensino Médio à Distância. No entanto, segundo os comentários dos entrevistados, eles tiveram acesso restrito ao laboratório de Informática e a alfabetização digital ainda não Ihes foi suficientemente oportunizada. Do grupo de entrevistados, Pink foi a única que apontou para a perspectiva de continuar estudando. Essa foi sua resposta: "Sim, eu quero continuar. Ah! Eu quero terminar, daí eu não digo fazê faculdade, mas terminar o segundo grau [sic]" (Pink,

13 Lei no 10.098, de 19 de dezembro de 2000. Estabelece normas gerais e critérios básicos para a promoção da acessibilidade das pessoas com deficiência ou com mobilidade reduzida (BRASIL, 2000b). 
20/11/2014). A seguir, relatou uma conversa que a professora titular realizou com a turma: "A professora falou pra nós estudar pra fazer o ENEM, que daí passa. Eu queria tentá fazê, sabe?" (Pink, 20/11/2014).

Esse conjunto de respostas permite refletir sobre os inúmeros fatores presentes na definição e na complexidade de se estabelecer projetos de futuro. Para Gilberto Velho, "as trajetórias dos indivíduos ganham consistência a partir de delineamento mais ou menos elaborado de projetos com objetivos específicos". Entretanto, segundo o mesmo autor, "a viabilidade de suas realizações vai depender do jogo e da interação com outros projetos individuais ou coletivos, da natureza e da dinâmica do campo de possibilidades" (Velho, 1994, p. 47). Resta então a questão de quanto e como a conclusão do Programa pode ter influído na reconstituição, reformulação ou ampliação do "campo de possibilidades" dos sujeitos dessa pesquisa. Esse é o mote de análise do próximo tópico, no qual se tratará das atividades desenvolvidas no Programa, com base na observação realizada ao longo do ano letivo.

\section{Reflexões com base nas observações do cotidiano escolar}

Como mencionado, a inserção na escola ocorreu no período de abril a dezembro de 2014. As observações pautaram-se por uma visão de pesquisa na qual o conhecimento é produzido pela capacidade do investigador de atribuir significados aos fenômenos analisados, ou seja, por uma epistemologia interpretativa. Nesta concepção, o investigador não é considerado um instrumento capaz de "aferir", mas sim como produtor da realidade, pois, na interação com os sujeitos investigados, ele produz o fenômeno ao produzir o significado dele. (Soares, 2006, p. 403). A seguir apontam-se três aspectos privilegiados no espaço desse artigo. O primeiro, a rotina das atividades escolares, o segundo, a dinâmica de reunião das escolas - quando do encerramento das atividades trimestrais - e, finalmente, a situação da turma após conclusão do Programa, considerando-se especialmente a continuidade ou não dos estudos.

Em relação ao primeiro aspecto, notou-se que a organização espacial predominante na sala de aula manteve-se nos moldes tradicionais. Os alunos permaneceram dispostos individualmente e enfileirados. Os exercícios e atividades realizados individualmente e, em caso de dúvidas, com o auxílio da professora. Não foram presenciadas atividades que demandassem interação, colaboração ou debate entre os alunos. Saliente-se que estas podem ter ocorrido em momentos distintos dos observados. Notou-se que os momentos de maior interação davam-se no refeitório ${ }^{14}$ e no pátio da escola. 
Nestes espaços, os alunos conversaram especialmente sobre suas rotinas diárias e ambiente trabalho.

O contraste entre o dinamismo das relações observado no pátio e o silêncio manifesto na rotina das aulas apontou para uma contradição entre a metodologia proposta no Regimento Programa - que define a construção do conhecimento com base na autonomia, cooperação, iniciativa, solidariedade, leitura crítica da realidade e aprendizagem contínua - e as práticas conteudistas que, a despeito de todas as críticas, ainda se encontram muito presentes no ambiente escolar.

O segundo aspecto observado foi o encontro trimestral das escolas que ofereciam - Programa, totalizando três turmas da modalidade Adulto e duas turmas da modalidade Adolescente. A reunião aqui analisada ocorreu no mês de agosto de 2014, no encerramento do segundo trimestre. Naquele momento, os alunos da escola investigada participaram encenando um telejornal intitulado "TV Integrada Adolescente/Adulto".

A coordenação da dinâmica esteve a cargo de três alunos. Inicialmente apresentaram reportagens e entrevistas filmadas na escola sobre o funcionamento do Programa e depoimentos da supervisora escolar e da orientadora educacional. Na sequência, entrevistaram, ao vivo, um aluno convidado, que encerrou a apresentação cantando um funk para todos. Segundo a professora titular, as entrevistas foram sugeridas por ela, pelos demais professores e pela vice-diretora. Naquele momento, reafirmouse a impressão de que o protagonismo e a autonomia dos alunos foram restritos e a percepção de que os momentos de maior interação ocorreram no intervalo das apresentações, quando os alunos da escola anfitriã serviram um lanche para os alunos das escolas convidadas e os diálogos ocorreram de forma mais espontânea. Tais ponderações, no entanto, não invalidam o esforço pedagógico realizado para o engajamento dos alunos, tampouco menosprezam os aprendizados e o desenvolvimento das habilidades mobilizadas para que pudessem preparar e apresentar a atividade.

O terceiro aspecto a ser examinado diz respeito à retomada do contato com os concluintes do Programa, durante os meses de maio e junho de 2015 , com o objetivo de verificar se eles haviam dado continuidade ou não aos estudos. A primeira constatação foi a de que já não seria possível localizar todos. As mudanças de endereços, números de telefone e outras contingências apontaram para a instabilidade muitas vezes presente no cotidiano das pessoas que enfrentam situações de precariedade na luta pela sobrevivência.

Contando com a ajuda de alguns dos entrevistados, conseguiu-se conversar com dez dos quatorze concluintes. Destes, metade não se matriculou no Ensino Médio e a outra metade afirmou ter ingressado em escolas estaduais da cidade, mas naquele momento já havia desistido. Uma alegação coincidente dos dois grupos foi a dificuldade de conciliar a rotina de estudo com as demandas familiares e de trabalho. 
Entretanto, preponderam nas respostas dos que tentaram e interromperam, queixas relativas ao desapontamento com a dinâmica dos novos ambientes escolares. Especialmente a divisão disciplinar do conhecimento, que resultava no contato fragmentado e, não raro superficial, com um número maior de docentes e pela difícil convivência com colegas adolescentes em sala de aula,ou seja, ressentiam-se da descontinuidade metodológica em relação à experiência no PAIA.

\section{Considerações finais}

Quando se iniciou a pesquisa aqui apresentada, havia certa tendência, um tanto ingênua, de considerar que o acesso e a finalização do Ensino Fundamental garantiriam aos alunos investigados a possibilidade e a intencionalidade de planejarem seu futuro. Esse planejamento, na hipótese original, deveria contemplar a continuidade dos estudos e, com isso, a garantia de maior estabilidade pessoal e profissional. A retomada do contato com os sujeitos da pesquisa mostrou o quão distante da realidade essa formulação estava.

A desestabilização causada por tal constatação demandou um novo esforço interpretativo. Este foi realizado com base na leitura das proposições do historiador François Hartog (2013), especialmente suas reflexões sobre o "regime de historicidade" dominante na sociedade contemporânea: o "presentismo". Resumidamente, pode-se dizer que essa noção elege o momento presente como definitivo, não conferindo relevância ao passado e não atribuindo esperanças ao futuro que passa a ser visto mais como ameaça do que como promessa. As demandas da manutenção da vida, da sobrevivência num "presente eterno", vivido na velocidade do instante, sem esperanças e sem planos de continuidade caracterizam a "ascensão do presentismo" (Hartog, 2013, p. 140).

Ao longo da investigação refletiu-se sobre o quanto as vivências escolares, em geral, e a experiência aqui analisada, em particular, estão imersas nessa lógica. As observações acima apresentadas identificaram rotinas que tanto desconsideram a riqueza da experiência de vida, do passado, dos alunos - que foram em alguma medida conhecidas nas entrevistas realizadas - quanto abrem mão de pensar possibilidades de futuro em conjunto com eles. Tal situação pode ser percebida, por exemplo, na descontinuidade metodológica observada na transição do Ensino Fundamental para o Médio e na inexistência de diálogo entre as esferas municipal e estadual que poderiam, trabalhando em conjunto, oferecer uma modalidade de ensino mais compatível com o público da EJA. Conclui-se que o Programa Ação Integrada Adultos tem méritos inegáveis, reconhece-se o engajamento dos profissionais envolvidos, mas nota-se ainda a necessidade de interação entre as formulações presentes nos documentos 
oficiais e a prática pedagógica cotidiana para que a passagem pelo PAIA possa mais efetivamente colaborar para a ampliação do campo de possibilidades presentes e futuras de seus egressos.

\section{Referências:}

ARIÈS, Philiphe. História Social da Infância e da Família. Rio de Janeiro: Zahar, 1981.

ARROYO, Miguel. Balanço da EJA: o que mudou nos modos de vida dos jovensadultos populares? REVEJ@ - Revista de Educação de Jovens e Adultos, Belo Horizonte, Grupo de Estudos e Pesquisas em EJA/UFMG, v. I, p. 1-108, ago. 2007.

BOURDIEU, Pierre. A economia das trocas simbólicas. São Paulo: Perspectiva, 2005.

BRASIL.Congresso Nacional. Lei no 10.098, de 19 de dezembro de 2000. DOU, Brasília, 20 dez. 2000.

BRASIL. Conselho Nacional de Educação. Resolução, n 1, 5 de Julho de 2000.

CALDEIRA, Liliam Cristina. Da escolarização à reinvenção de si: os sentidos da aprendizagem para o educando da EJA. 2011. Tese (Doutorado em Educação), PPG-Educação, UFMGS, 2011.

DRUCK, Maria da Graça. Globalização e reestruturação produtiva: o Fordismo e/ ou Japonismo. Revista de Economia Política. São Paulo, FGV, Vol. 19, n. 2 (74), p. 31-48, abr-jun.1999.

ESTEIO. Prefeitura Municipal. Secretaria Municipal de Educação e Esporte. Regimento Padrão do Programa Ação Integrada para Adultos. Gestão 2009-2012.

FERRARI, Greicimara Vogt. Trajetórias escolares da Educação de Jovens e Adultos: singulares em contextos plurais. Dissertação (Mestrado em Educação), PPGEducação, UNISINOS, 2014.

HARTOG, François. Regimes de historicidade: presentismo e experiências no tempo. Belo Horizonte: Autêntica Editora, 2013.

JOSSO, Marie-Christine. Os relatos de histórias de vida como desvelamento dos desafios existenciais da formação e do conhecimento. In: ABRAHÃO, Maria Helena Menna Barreto; SOUZA, Eliseu Clementino de (Orgs.). Tempos, narrativas 
e ficções: a invenção de si. Porto Alegre: EDIPUCRS, 2006, p. 21-40.

KUHLMANN, Moysés Jr. Histórias da educação infantil brasileira. Revista Brasileira de Educação, Rio de Janeiro, Anped, n. 14, p. 5-18, maio-ago. 2000.

MANZINI, Eduardo José. Uso da entrevista em dissertações e teses produzidas em um Programa de Pós-Graduação em Educação. Revista Percurso, Maringá, NEMO-Nucleo de Estudos de Mobilidade e Mobilização/UEM, v. 4, n. 2, p. 149171, jul-dez. 2012.

MOREIRA, Thereza Maria Magalhães; VIANA, Danielle de Sousa; QUEIROZ, Maria Veraci Oliveira; JORGE, Maria Salete Bessa. Conflitos vivenciados pelos adolescentes com a descoberta da gravidez. Revista da Escola de Enfermagem/ USP, São Paulo, v. 42, n. 2, p. 312-320, jul-dez. 2008.

OLIVEIRA, Elzira Lúcia de, RIOS-NETO, Eduardo Gonçalves; OLIVEIRA, Ana Maria Camilo de. Transições dos jovens para o mercado de trabalho. Revista Brasileira de Estudos de População, São Paulo, Associação Brasileira de Estudos Populacionais, v. 23, n. 1, p. 109-127, jan-jun. 2006.

POLLAK. Memória e identidade social. Estudos Históricos, Rio de Janeiro, CPDOC/ FGV, v. 5, n. 10, p. 200-212, jul-dez.1992.

Quadros, Claudemir de. Marcas do tempo: imagens e memórias das brizoletas. Santa Maria: Unifra, 2005.

SOARES, Magda. Pesquisa em Educação no Brasil - continuidades e mudanças. Um caso exemplar: a pesquisa sobre alfabetização. Revista Perspectiva, Florianópolis, UFSC, v. 24, n. 2, p. 393-417, maio-ago. 2006.

VALE, Elisabete Carlos do. A EJA nos contextos de escolarização e as possibilidades de práticas educativas emancipatórias. 2012. Tese (Doutorado em Educação), PPG-Educação, UERJ, 2012.

VELHO, Gilberto. Projeto e metamorfose: antropologia das sociedades complexas. Rio de Janeiro: Zahar, 1994. 
Recebido em junho de 2016

Aceito em junho de 2017

Márcia Regina da Silva é Mestra em Educação pela Universidade do Vale do Rio dos Sinos/Unisinos. Professora da Rede Municipal de Ensino de Esteio/RS. Integrante do grupo de pesquisa Mediações Pedagógicas e Cidadania (CNPq). Email: maresiasol@ outlook.com

Isabel Bilhão é Doutora em História Social pela Universidade Federal do Rio Grande do Sul/UFRGS. Professora do Programa de Pós-Graduação em Educação da Universidade Vale do Rio dos Sinos/Unisinos. Pesquisadora dos grupos de pesquisa Mediações Pedagógicas e Cidadania e Educação no Brasil: memória, instituições e cultura escolar (CNPq).Email: iabilhao@gmail.com 